\title{
Agency and Structure: A social simulation of knowledge-intensive industries
}

\section{Affiliation of authors}

Petra Ahrweiler

UCD Innovation Research Unit IRU, CASL, University College Dublin, Ireland Email:petra.ahrweiler@ucd.ie, Tel: +35317168919 Fax: +35317165396

Nigel Gilbert

School of Human Sciences, University of Surrey, Guildford, Surrey, United

Kingdom

Email:n.gilbert@surrey.ac.uk

Andreas Pyka

Economics Department, University of Hohenheim, Germany

E-Mail:a.pyka@uni-hohenheim.de: Tel: + 49711 459-24481 Fax: + 49711

$459-24488$

\section{Footnotes}

1 "The Lisbon agenda is currently the agenda for socio-economic development of the European Union. It was adopted by the European Council of Lisbon in 2000 and it is reshaping many of the Community policies as well as being translated into National Reform programmes in all Member States" (Lisbon Agenda Group 2007). 


\title{
Agency and Structure: A social simulation of knowledge-intensive industries
}

\begin{abstract}
Modern knowledge-intensive economies are complex social systems where intertwining factors are responsible for the shaping of emerging industries: the self-organising interaction patterns and strategies of the individual actors (an agency-oriented pattern) and the institutional frameworks of different innovation systems (a structureoriented pattern). In this paper, we examine the relative primacy of the two patterns in the development of innovation networks, and find that both are important. In order to investigate the relative significance of strategic decision making by innovation network actors and the roles played by national institutional settings, we use an agent-based model of knowledge-intensive innovation networks, SKIN. We experiment with the simulation of different actor strategies and different access conditions to capital in order to study the resulting effects on innovation performance and size of the industry. Our analysis suggests that actors are able to compensate for structural limitations through strategic collaborations. The implications for public policy are outlined.
\end{abstract}

Keywords: innovation networks, agent-based social simulation, innovation systems

\section{Introduction}

"Although many different factors contribute to Europe's performance in competitiveness and employment, Research, Technology and Development (RTD) and innovation are critical among them as they affect companies' long term capacity to stay in the market as active players, to maintain and renew their range of products and services and ultimately to create conditions for sustainable employment. The demands on and expectations from RTD policies to deliver on competitiveness and 
employment have hence been increasing strongly" (Commission of the European Communities 2002: 13).

In Europe's knowledge-based economies the mechanisms of knowledge creation and utilisation have been changing, with an increasing emphasis on the formation of innovation networks, that is, networks which connect innovative firms, government agencies, research institutes and sources of venture capital. Economic sociology and new innovation economics consider the growing complexity of knowledge, the accelerating pace of knowledge creation, and the shortening of industry life cycles to be responsible for the rising importance of innovation networks (e.g. Powell et al. 2005, Eliasson 1995). Knowledge-intensive industries such as information and communication technologies (ICT) and biotechnology ('biotech') have already undergone structural changes in the direction of these collective modes of knowledge production and application. Emerging industries, such as those based on new materials and nanotechnologies as well as knowledge-based services, are also developing along these lines. Combining knowledge resources in social networks enables innovation and learning that are difficult to provide by other means. Decreasing risks by distributing them to network members and accessing financial funds for the capital needed in product development are additional motives in these industries.

These changes are reflected in the social sciences: although the institutional approach in economics has already introduced a sociological perspective to mainstream economic theory, sociologists such as Granovetter (1985) and others have criticised the approach, arguing that actual markets are shaped by social factors to a much larger degree than institutional economics allows. 'Social shaping' refers not only to the fact that real markets rely on the co-operative behaviour of their members, that is, 
on the institutional regulations that frame the interactions of traders, but also to the social role of the networks of collaborations and contracts that are an integral part of most markets.

The changes are occurring throughout the world. For example, a comparison of the current structures and dynamics of UK and German biotechnology-based industries reveals a striking convergence of industrial structure and the directions of innovation in both countries (reference to authors). This counteracts propositions from conventional neo-institutionalist frameworks such as the varieties-of-capitalism hypothesis and the national innovation systems approach which suggest that there are substantial differences between the industrial structures of European countries due to differing institutional frameworks (cf. Casper and Kettler 2001). The observed structural alignment can be explained by the network organisation of research and production in knowledge-based industries.

Nevertheless, this does not diminish the importance of structural contexts: "At the start of the twenty-first century the role of institutions and the conditions for institutional change are at the core of the economic debate in Europe" (Amable 2003: 1). There is strong empirical evidence (cf. Amable 2003, Casper and van Waarden 2006) that institutional framework conditions shape the structure and dynamics of societies: each national society has developed a context and a path dependent institutional infrastructure (politics, law, economy, culture) and, because economic action is strongly influenced by these specific infrastructures, this leads to differences in national industrial performance. However, in knowledge-intensive industries the structures of industrial R\&D organization in different countries are tending to converge, triggered by the particular challenges of knowledge generation and diffusion. 
Modern knowledge-intensive economies are complex social systems where intertwining factors are responsible for the shaping of emerging industries: the selforganising interaction patterns and strategies of the individual actors (an agencyoriented pattern) and the institutional frameworks of different innovation systems (a structure-oriented pattern). Policy is changing from a neo-liberal model (based on improving institutions for financing and technology transfer) towards a so-called "good governance model", which mainly stresses the complex, non-linear, interdependent, and adaptive features of social systems.

Economic sociology tries to capture these complex features while being aware of the pitfalls of an agency-structure dichotomy. The agency-oriented pattern is put in focus by Powell et al. whose aim "is to illuminate how patterns of interaction emerge, take root, and transform, with ramifications for all of the participants. We develop arguments concerning how the topology of a network and the rules of attachment among its constituents guide the choice of partners and shape the trajectory of the field" (Powell et al. 2005: 5). Borrowing the notion from Bourdieu (1992), Powell et al. recognise "fields" as communities of organisations that engage in common activities and are subject to similar reputational and regulatory pressures defining them as networks of relations between positions.

For Powell et al., the dynamics of innovation networks, which they define as interaction patterns between two or more actors, can explain how fields evolve. They relate the behaviour and dynamics of the entire structure to the properties of its constituents and their interactions: individual firms learn how to collaborate with a very heterogeneous set of partners. Field evolution can be explained by the mechanisms for partner 
selection (Powell et al. 2005: 7f). The strategic decisions of the networking actors and their engagement in different learning activities are responsible for the shaping of the industry. The focus is on representing the agency of innovative actors who are located in an institutional framework, on the interactions of participants and the emerging network dynamics and thus on the evolution of the industrial field.

In contrast, structure-oriented patterns of explanation emphasise the important role played by the specific national institutional settings for the innovative performance of an economic system. As the sociological version of the "varieties of capitalism" (VoC) thesis states, national industries do look different. Each formation can offer a particular comparative institutional advantage, enabling economic success within the different national frameworks (Hall and Soskice 2001). VoC studies (Petit and Amable 2001; Amable 2003) investigate the differences between "liberal market economies" (such as the UK) and "co-ordinated market economies" (such as Germany). The differences are traced back to national regulations of labour and corporate law, to institutional differences in the development of competences and knowledge transfer, and to differences in financial systems, e.g. the availability of venture capital and public funding for start-ups. Differentiating, elaborating and complementing the focus on framework conditions, recent research has targeted sectoral systems of innovation (Malerba 2002), regional innovation systems (Cooke and Morgan 1998) and local technology clusters (Feldman et al. 2005).

Just as Powell et al. are well aware of the field constraints and framework conditions working on and in agency-oriented patterns, framework theorists are sensitive to the importance of an actor-centered view. According to Beije (1998: 256), an innovation system must "be defined as a group of private firms, public research institutes, and 
several of the facilitators of innovation, who in interaction promote the creation of one or a number of technological innovations [within a framework of] institutions which promote or facilitate the diffusion or application of these technological innovations".

Bourdieu offers an elaborated operationalisation of the structure-oriented pattern. For him, it is the structures and the constraints of the field which enable and limit opportunities for actors: "Firms undertake actions there which depend, for their ends and effectiveness, on their position in the field of forces, that is to say, in the structure of distribution of capital in all its species“ (Bourdieu 2005: 199). Capital, for Bourdieu, is not only financial capital but all the resources an actor can draw upon, e.g. technological, financial, commercial, social and symbolic capital. The changing distribution and (re-)combination of capital in this sense - the field - is responsible for the shaping of the industry. With that, "field theory stands opposed [...] to the interactionist vision, which is, by virtue of the representation of the agent as a calculating atom, able to cohabit with the mechanistic vision, and according to which the economic and social order can be reduced to a host of interacting individuals, most often interacting on a contractual basis" (Bourdieu 2005: 197).

\section{Social simulation}

Untangling the various relationships posited by Bourdieu, Powell et al. and other commentators is particularly difficult because of the nature of the phenomenon: innovative industrial sectors are by definition constantly changing. Tracking the influence of particular characteristics is most effectively done with an experimental design, yet, as with most matters of sociological interest, direct experiments are 
impossible, impracticable or unethical. Moreover, most renderings of innovation theory are vague and incomplete, making testing doubly difficult.

Agent-based social simulation can come to the rescue. Agent-based simulation enforces the precise articulation of theory and enables a dynamic representation of theories and empirical knowledge about innovative actors and their networking behaviours. In this context, "agents" are computer programs that directly represent in software theories about the attributes, properties and actions of empirical actors. Each agent in such a system is autonomous, pro-active, reactive, able to interact, able to learn, and has an individual state depending on context, situation, and time. Agent-based models are usually based on a set of autonomous agents capable of interacting with each other as well as with the environment according to pre-specified rules of behaviour. From the interaction on the micro-level emerge macro-level features as system properties. Figuratively, we build an "artificial society" in the computer to carry out the experiments that we would have liked to perform in the empirical world. We can observe the dynamic processing of our theories, using, as Collins (1995: 288) said, "a kind of natural laboratory for testing (science studies') ideas". If it produces artificial data that resemble those we observe empirically this gives some indication of the quality, consistency and completeness of our theories and interpretations of complex interaction patterns. Thus, agent-based simulation offers new opportunities to investigate the relationships between variables describing complex scenarios that would not be possible using more conventional methods.

To model knowledge-intensive industries, we follow the idea of "history-friendly" modelling: 
History-friendly models are formal models which aim to capture - in stylized form - qualitative theories about mechanisms and factors affecting industry evolution, technological advance and institutional change put forth by empirical research in industrial organization, in business organization and strategy, and in the histories of industries. They present empirical evidence and suggest powerful explanations. Usually these "histories" are very rich and detailed. Actors and variables like the educational system, policies, institutions, the internal organizational structure of firms, the structure of demand play a fundamental role in these accounts. Modeling the history of industry necessarily implies a more rigorous dialogue with empirical evidence and with non-formal explanations of those histories, i.e. with "appreciative theorizing". This is particularly relevant because many explanations used in historical analysis are so rich and complex that only a simulation model can capture (at least in part) the substance, above all when verbal explanations imply nonlinear dynamics (Malerba et al. 1999: 3-4).

The agent-based simulation SKIN models the trading of firms and their changing knowledge levels within knowledge-intensive industries. SKIN is grounded in empirical research and theoretical frameworks from innovation economics and economic sociology. The agents represent innovative firms who try to sell their innovations to other agents and end users but who also have to buy raw materials or more sophisticated inputs from other agents (or material suppliers) in order to produce their outputs. This basic model of a market is extended with a representation of the knowledge dynamics in and between the firms. Each firm tries to improve its innovation performance and its sales by improving its knowledge base through adaptation to user needs, incremental or radical learning, and co-operation and networking with other 
agents. This section will describe the elements and processes of this model (refences to authors). The SKIN model is the result of a number of projects that combined empirical research into innovation networks with agent-based simulation ${ }^{1}$.

${ }^{1}$ This work started with the EU project "Simulating self-organising Innovation Networks" (SEIN). This project combined five empirical case studies in different sectors of technological innovation and in different EU member states with agentbased simulation of these case studies. The results of the SEIN project are summarised in Pyka and Kueppers (2003). Case studies described knowledgeintensive European industry sectors such as the biotechnology-based pharmaceutical industry in France (Pyka and Saviotti 2003), combined heat and power technology networks in The Netherlands, Germany and the UK (Weber 2003), knowledgeintensive business services in the UK web design industry (Windrum 2003), and the UK Virtual Centre of Excellence in the European telecommunication industry (reference to authors 2003). The task of the SEIN project was threefold: theory formation, empirical case studies, and agent-based simulation. The objective was to derive a theory of innovation networks from insights derived inductively from the case studies and to implement this theory of innovation networks into an agent-based model $^{1}$. The result of the modelling activities was an agent-based model - based on empirical research and informed by empirical data coming from the case studies (reference to authors). The model was used by the European Commission for scenario modelling of current and future innovation policy strategies (reference to authors) referring to the technological sectors and EU Member States of the case studies. 
The current SKIN model builds on the procedures we implemented for biotechnologybased pharmaceuticals in Europe using this sector as an example par excellence of a knowledge-intensive industry. Therefore, when showing in more detail how the model procedures are rooted in empirical research, we will focus on this industrial sector specifically. The empirical work ${ }^{2}$ is summarised in reference to authors (2006). The model is concerned with representing the agency of innovative actors within an institutional framework: network dynamics arise from the interaction of firms, and field evolution can be observed on the industry level.

In experimenting with the simulation we are able to investigate the influences of agency-oriented and structure-oriented patterns on the agent population. We can show and measure the influence of the interaction and the strategies of the individual actors (agency-oriented pattern) and the influence of structural features evolving through the ever changing knowledge and capital distribution opening up new opportunities for actors or limiting their action space (structure-oriented pattern). In the rest of this section we introduce the model. In section 3 we summarise what we learnt from the SKIN model through experimenting with agency-oriented and structure-oriented patterns of industry evolution. First, the elements and processes of the model are described in more detail.

\subsection{The agents}

Using Bourdieu's terms, a SKIN agent is a firm which owns "technological capital", i.e. "the portfolio of scientific resources (research potential) or technical resources

\footnotetext{
${ }^{2}$ Empirical research for refining the SKIN procedures has been conducted in the bi-national research project of the British Council and the German DAAD "Comparing German and UK biotechnologybased pharmaceuticals: Simulating Knowledge Dynamics in Innovation Networks" (SKIN).
} 
(procedures, aptitudes, routines and unique and coherent know-how, capable of reducing expenditure in labour or capital or increasing its yield) that can be deployed in the design and manufacture of products" (Bourdieu 2005: 194). This technological capital is the individual knowledge base of a firm. It is called the firm's kene (reference to authors) and it consists of a number of "units of knowledge". Each unit is represented as a triple consisting of a firm's capability $C$ in a scientific, technological or business domain (e.g. biochemistry), represented by an integer randomly chosen from the range of $1 . .1000$, its ability $A$ to perform a certain application in this field (e.g. a synthesis procedure or filtering technique in the field of biochemistry), represented by an integer randomly chosen from the range $1 . .10$ and the expertise level $E$ the firm has achieved with respect to this ability (represented by an integer randomly chosen from the range 1..10). The firm's kene is its collection of C/A/E-triples (figure 1).

$\left\{\begin{array}{l}C_{1} \\ A_{1}^{1} \\ E_{1}^{1}\end{array}\right\},\left\{\begin{array}{l}C_{1} \\ A_{2}^{1} \\ E_{2}^{1}\end{array}\right\}, \ldots,\left\{\begin{array}{c}C_{2} \\ A_{1}^{2} \\ E_{1}^{2}\end{array}\right\}, \ldots,\left\{\begin{array}{c}C_{2} \\ A_{n}^{2} \\ E_{n}^{2}\end{array}\right\}, \ldots,\left\{\begin{array}{c}C_{n} \\ A_{1}^{n} \\ E_{1}^{n}\end{array}\right\}, \ldots$

Figure 1: The kene of an agent

Firms apply their knowledge to create innovative products that have a chance to be successful in the market. The special focus of a firm, its potential innovation, is called an innovation hypothesis. In the model, the innovation hypothesis $(\mathrm{IH})$ consists of a subset of the firm's kene triples. Each firm starts with a stock of initial financial capital, which is "the direct or indirect mastery of financial resources, which are the main condition (together with time) for the accumulation and conservation of all other kinds of capital“ (Bourdieu 2005: 194). The firm needs this capital to produce for the market and to improve its knowledge base, and it can increase its capital by selling products. 


\subsection{The market}

Because actors in empirical innovation networks of knowledge-intensive industries interact on both the knowledge and the market levels (cf. Garcia et al. forthcoming b: 2), we need a representation of market dynamics in the SKIN model. Agents are therefore characterised by their capital stock. Each firm, when it is set up, has a stock of initial capital. It needs this capital to produce for the market and to finance its R\&D expenditures; it can increase its capital by selling products. The amount of capital owned by a firm is used as a measure of its size and additionally influences the amount of knowledge (measured by the number of triples in its kene) that it can maintain. In many knowledge-intensive industries we find the co-existence of large and small actors (e.g. the large pharmaceutical firms and biotech start-ups, and the former national monopolists and high technology specialists in the ICT industries, cf. Pyka and Saviotti 2005). We assume that large diversified firms are characterised by a larger knowledge base as compared with smaller specialised companies (cf. Brusoni et al. 2001). Most firms are initially given the same starting capital allocation, but in order to model differences in firm size, a few randomly chosen firms can be allocated significant extra capital to represent the large companies.

Firms apply their knowledge to create innovative products that have a chance of being successful in the market. "Most technology is specific, complex... (and) cumulative in its development... It is specific to firms where most technological activity is carried out, and it is specific to products and processes, since most of the expenditures is not on research, but on development and production engineering, after which knowledge is also accumulated through experience in production and use 
on what has come to be known as "learning-by-doing" and "learning-by-using"' (Pavitt 1987: 9).

The underlying idea for an innovation, modelled by the innovation hypothesis $(\mathrm{IH})$, is the source an agent uses for its attempts to make profits in the market. Because of the fundamental uncertainty of innovation (Knight 1921), there is no simple relationship between the innovation hypothesis and product development. To represent this uncertainty, we developed the following mechanism: the innovation hypothesis is transformed into the simulation of a product through a mapping procedure where the capabilities of the innovation hypothesis are used to compute an index number that represents the product. The particular transformation procedure applied allows the same product to result from different kenes, which is not too far from reality where the production technologies of firms within a single industry can vary considerably (Winter 1984).

A firm's product, $P$, is generated from its innovation hypothesis as

$$
P=\left(\sum_{I H} C_{i}\right) \bmod N
$$

(where $\mathrm{N}$ is a constant representing the maximum number of different possible products).

A product has a certain quality, which is also computed from the innovation hypothesis in a similar way, by multiplying the abilities and the expertise levels for each triple in the innovation hypothesis and normalising the result. In order to realise the product, the agent needs some materials. These can either come from outside the sector ("raw materials") or from other firms, which generated them as their 
products. Which materials are needed is also determined by the underlying innovation hypothesis: the kind of material required for an input is obtained by selecting subsets from the innovation hypothesis and applying the standard mapping function (equation 1).

These inputs are chosen so that each is different and differs from the firm's own product. In order to be able to engage in production, all the inputs need to be obtainable on the market, i.e. provided by other firms or available as raw materials. If the inputs are not available, the firm is not able to produce and has to give up this attempt to innovate. If there is more than one supplier for a certain input, the agent will choose the one at the cheapest price and, if there are several similar offers, the one with the highest quality.

If the firm can go into production, it has to find a price for its product, taking into account the input prices it is paying and a possible profit margin. While the simulation starts with product prices set at random, as the simulation proceeds a price adjustment mechanism following a standard mark-up pricing model increases the selling price if there is much demand, and reduces it (but no lower than the total cost of production) if there are no customers. Some products are considered to be destined for the 'end-user' and are sold to customers outside the sector: there is always a demand for such end-user products provided that they are offered at or below a fixed end-user price. A firm buys the requested inputs from its suppliers using its capital to do so, produces its output and puts it on the market for others to purchase. Using the price adjustment mechanism, agents are able to adapt their prices to demand and in doing so learn by feedback. 
In making a product, a firm applies the knowledge in its innovation hypothesis and this increases its expertise in this area. This is the way that learning by doing/using is modelled. The expertise levels of the triples in the innovation hypothesis are increased and the expertise levels of the other triples are decremented. Expertises in unused triples in the kene are eventually lost and the triples are then deleted from the kene; the corresponding abilities are "forgotten" or "dismissed" (cf. e.g. Hedberg 1981).

Thus, in trying to be successful in the market, firms are dependent on their innovation hypotheses, i.e. on their kenes. If a product does not meet any demand, the firm has to adapt its knowledge in order to produce something else for which there are customers (cf. e.g. Duncan 1974). A firm has several ways of improving its performance, either alone or in co-operation, and in either an incremental or a more radical fashion.

\subsection{Learning and co-operation: improving innovation performance}

In an earlier publication (reference to authors 2007), we showed how these learning features of the SKIN model are theoretically grounded in the body of literature known as "Organizational Learning" (OL). After Dewey (1938) introduced the concept of experiential learning as a permanent activity cycle and started a discussion among educationalists about feedback learning and learning by doing, Michael (1973) coined the term, organisational learning. Argyris and Schön's influential monograph, Organizational Learning (1978; newly edited including further work as Organizational Learning II, 1996) proposed that a learning organisation is one that is permanently 
changing its interpretation of the environment. In doing so, the organisation learns new things and forgets old ones. Drawing on their background as action theorists, Argyris and Schön show how these interpretations are gained and how they are connected to different organisational behaviours. They distinguish between three types of learning, rooting them in an understanding of organisational agency that targets growth and effectiveness:

- $\quad$ Single-loop learning: This is adjustment learning, referring to the rational use of one's own means and instruments to adapt to environmental requirements, given a set of organisational goals, strategies and behaviours. It targets an improvement of the "theory in use" of an organisation using a simple action-outcome feedback and follows the heuristic, "maximise gains and minimise loss".

- Double-loop learning: This is turnover learning with respect to the meta-level of goals, strategies, and behaviours of an organisation, and aims to adapt them to environmental requirements. The learning process includes un-learning of redundant knowledge to clear space for new behaviours. Furthermore, co-operation, including assumption and benefit sharing with collaborators, is seen as a vehicle for learning.

- Deutero learning: This is meta-level learning of the highest order where the organisation reflects on its own identity. Here, the learning process itself is the object of learning ("to learn how to learn"). The organisation's norms and values are subject to critique and change.

The SKIN model takes many of the ideas of the Argyris and Schön framework and uses them to examine the assumption that, in the words of de Geus (1997), the greatest competitive advantage for any firm is its ability to learn. Experiments concerning the effects of different combinations of learning activities on the agent population are reported in (reference to authors 2007). In the SKIN model, firms 
predominantly engage in single- and double-loop learning activities. Deutero learning may appear when new agents intentionally are created by collaborating actors due to the success of the network.

In respect of single loop learning, firm agents can:

- use their capabilities (learning by doing/using) and learn to estimate their success via feedback from markets and clients (learning by feedback) as already mentioned above

- improve their own knowledge incrementally when the feedback is not satisfactory in order to adapt to changing technological and/or economic standards (adaptation learning, incremental learning)

If a firm's previous innovation has been successful, i.e. it has found buyers, the firm will continue selling the same product in the next round, possibly at a different price depending on the demand it has experienced. However, if there were no sales, it considers that it is time for change. If the firm still has enough capital, it will carry out "incremental" research (R\&D in the firm's labs). Performing incremental research (cf. Cohen and Levinthal 1989) means that a firm tries to improve its product by altering one of the abilities chosen from the triples in its innovation hypothesis, while sticking to its focal capabilities. The ability in each triple is considered to be a point in the respective capability's action space. To move in the action space means to go up or down by an increment, thus allowing for two possible "research directions".

Alternatively, firms can radically change their capabilities in order to meet completely different client requirements (innovative learning, radical learning). A SKIN firm agent under serious pressure and in danger of becoming bankrupt, will turn to more radical measures, by exploring a completely different area of market opportunities. In the model, an agent under financial pressure turns to a new innovation hypothesis after 
first "inventing" a new capability for its kene. This is done by randomly replacing a capability in the kene with a new one and then generating a new innovation hypothesis.

Firms may also be also active on the double-loop learning level of the model. They can:

- forget their capabilities (clean up their knowledge space)

- decide on their individual learning strategies themselves (e.g. incremental or radical learning), constructing and changing the strategies according to their past experience and current context. The context consists of external factors such as the actions of clients, competitors and partners and the availability of technical options, and internal factors such as their capital stock and the competencies available to them

- engage in networking and partnerships to absorb and exploit external knowledge sources, to imitate and emulate, and to use synergy effects (participative learning).

An agent in the model may consider partnerships (alliances, joint ventures etc.) in order to exploit external knowledge sources. The decision whether and with whom to co-operate is based on the mutual observations of the firms, which estimate the chances and requirements coming from competitors, possible and past partners, and clients. Bolton, Katoka and Ockenfels (2005), writing from a theoretical viewpoint, and Mitchelet (1992), using empirical evidence, both show that greater mutual information, where firms know their partner's history of cooperation, improves the conditions for cooperation. In the SKIN model, a marketing feature provides the information that a firm can gather about other agents: to advertise its product, a firm publishes the capabilities used in its innovation hypothesis. Those capabilities not 
included in its innovation hypothesis and thus in its product are not visible externally and cannot be used to select the firm as a partner. The firm's 'advertisement' is then the basis for decisions by other firms to form or reject co-operative arrangements.

In experimenting with the model, we can choose between two different partner search strategies (Powell et al. 2005), both of which compare the firm's own capabilities as used in its innovation hypothesis and the possible partner's capabilities as seen in its advertisement. Applying the conservative strategy, a firm will be attracted to a partner that has similar capabilities; using a progressive strategy the attraction is based on the difference between the capability sets.

Previously good experience with former contacts generally augurs well for renewing a partnership. For example, Garcia's et al. findings concerning the interaction patterns between public research centres and industrial firms confirm that "prior formal relationships are a fundamental element for collaboration... Strong ties (past relationships) appear to be more fundamental in building university-industry ties" (Garcia et al. forthcoming a: 2f). This is mirrored in the model: to find a partner, the firm will look at previous partners first, then at its suppliers, customers and finally at all others. If there is a firm sufficiently attractive according to the chosen search strategy (i.e. with attractiveness above the 'attractiveness threshold'), it will stop its search and offer a partnership. If the potential partner wishes to return the partnership offer, the partnership is set up.

The model assumes that partners learn only about the knowledge being actively used by the other agent. Thus, to learn from a partner, a firm will add the triples of the partner's innovation hypothesis to its own. For capabilities that are new to it, the expertise levels of the triples taken from the partner are reduced in order to mirror the 
difficulty of integrating external knowledge as stated in empirical learning research (cf. Cohen and Levinthal 1989, Cantner and Pyka 1998). For partner's capabilities that are already known to it, if the partner has a higher expertise level, the firm will drop its own triple in favour of the partner's one; if the expertise level of a similar triple is lower, the firm will stick to its own version. Once the knowledge transfer has been completed, each firm continues to produce its own product, possibly with greater expertise as a result of acquiring skills from its partner.

If the firm's last innovation was successful, i.e. the value of its profit in the previous round was above a threshold, and the firm has some partners at hand, it can initiate the formation of a network. A network of firms in the biotechnology-based pharmaceutical sector often forms an independent legal entity. An example is Genostar, a French bio-informatics company which emerged from a public-private innovation network between the Institut Pasteur, INRIA (French National Institute for Research in Computer Science and Control), and the firms Genome Express, and Hybrigenics. ${ }^{3}$ The formation of a legal entity enables actions and exploits advantages that are only available to companies and can be considered as a particular form of deutero learning. This is why networks are autonomous agents in the SKIN model. Of course, the participating members stay autonomous agents themselves and thus have a chance for double profit: the distributed rewards if the network is successful, and the returns they get from their own successful innovation projects that they undertake outside of the network.

Networks are "normal" agents, i.e. they get the same amount of initial capital as other firms and can engage in all the activities available to other firms. The kene of a

\footnotetext{
${ }^{3}$ See http://www.genostar.com/en/about-genostar/history1.html
} 
network is the union of the triples from the innovation hypotheses of all its participants. If a network is successful it will distribute any earnings above the amount of the initial capital to its members; if it fails and becomes bankrupt, it will be dissolved.

\subsection{Start-ups}

If a sector is successful, new firms will be attracted into it representing Schumpeterian competition by imitation. This is modelled by adding a new firm to the population when any existing firm makes a substantial profit. The new firm is a clone of the successful firm, but with its kene triples both restricted to those in the successful firm's advertisement and set to a low expertise level. This models a new firm copying the characteristics of those seen to be successful in the market. As with all firms, the kene may also be restricted because the initial capital of a start-up is limited and may not be sufficient to support the copying of the whole of the successful firm's innovation hypothesis.

\section{Agency and structure: the experiments}

To test our research question about the relative importance of the structure and the agency orientations, we perform numerical experiments with opposing conditions for the initial distribution and the strategic orientation of actors. This research strategy highlights the twofold advantages agent-based modelling offers for this kind of analysis: on the one hand, this strict distinguishing between the two scenarios can 
never be achieved empirically. On the other hand, the ABM allows for the simulation and investigation of a wide range of factors concerning innovation performance, knowledge development etc. although they are empirically not or only incompletely available for analysis.

In experimenting with the SKIN model we compare an agency-oriented scenario and a structure-oriented scenario using two dependent variables, the innovative success of the sector and its size, measured by the number of firms in the sector.

Within the agency-oriented scenario, we test whether the strategic collaboration decisions of actors are responsible for the shaping of the sector (size and innovative performance). We ask whether it makes any difference to the sector's success and the number of firms if
a) firms decide against strategic collaboration, i.e. neither form partnerships nor networks, or
b) use different mechanisms of partner choice.

If the simulation experiments suggest a positive answer to both questions this supports a perspective which claims the primacy of an agency-oriented pattern in industry formation. Then, the strategic collaboration decisions of actors, i.e. their interaction patterns, could be responsible for the shaping of the field.

To operationalise (a), we switch off the ability of firms to collaborate; to operationalise (b) we choose first the conservative (independent variable called "conservative") and then the progressive (independent variable called "progressive") partner choice 
strategy as the only mechanism available for partner-seeking firms. Within these scenarios we test the influence of our changes on the innovative performance measured by the number of innovations in the sector (dependent variable called "I") and on the sector size measured by the number of firms remaining in the population after a certain period (dependent variable called "N").

Within the structure-oriented scenario, we ask whether structural features determine the options and limitations of actors and therefore shape the sector. The permanently changing distribution and (re)combination of types of capital (Bourdieu's "field") is used to represent structural conditions (availability of funding and venture capital, availability of human resources, technology and knowledge transfer institutions etc.).

Here, we ask whether it makes any difference for the success of the sector and the number of firms if
a) all firms initially have the same capital available to them or
b) firms differ greatly in owning various kinds of capital

If the simulation experiments show that this indeed makes a significant difference, the claim of a structure-oriented pattern of sector formation is supported. Then, chances and constraints of the field, i.e. its structure, could be responsible for the shaping of the sector in terms of size and innovative performance.

To operationalise (a) in the structure-oriented scenario, we distribute all capital equally between the agents. To operationalise (b), the number of big firms (represented in the model as having ten times the amount of technological and 
financial capital of the remaining firms) is varied (independent variable called „uniformsize"). We again test the influence of the changes on innovative performance and on sector size.

Two regression models are estimated to measure the influence of the independent variables (uniformsize, conservative, progressive) on the number of innovations (I) and on the size of the sector $(\mathrm{N})$. Table 1 details the results of the regressions based on 10 simulation runs, each lasting 200 time steps, at the end of which the number of innovations and the number of firms were counted ${ }^{4}$. We chose time $=200$ as the stopping point because at that time the simulation system is "warmed up" sufficiently to show us the effect of different collaboration strategies.

\section{Regression results}

\begin{tabular}{|c|c|c|c|c|c|c|}
\hline & \multicolumn{3}{|c|}{ I (number of innovations) } & \multicolumn{3}{|c|}{ N (number of firms) } \\
\hline & $\begin{array}{l}\text { Regression } \\
\text { coefficient }\end{array}$ & $\begin{array}{l}\text { Standard } \\
\text { error }\end{array}$ & $\beta$-values & $\begin{array}{l}\text { Regression } \\
\text { coefficient }\end{array}$ & $\begin{array}{l}\text { Standard } \\
\text { error }\end{array}$ & $\beta$-values \\
\hline Intercept & 8682 & 62.660 & & 367 & 32.718 & \\
\hline Uniformsize & $-117^{*}$ & -8.501 & -0.595 & $-34^{*}$ & -3.048 & -0.237 \\
\hline Conservative & $1476^{*}$ & 8.698 & 0.703 & $137^{*}$ & 9.977 & 0.895 \\
\hline Progressive & $811^{*}$ & 4.782 & 0.386 & $79^{*}$ & 5.814 & 0.522 \\
\hline $\mathrm{R}^{2}$ & 0.726 & & & 0.662 & & \\
\hline
\end{tabular}

Table 1: Estimates from regression models for the number of innovations and number of firms against the capital distribution (uniformsize) and partnering strategy (none; conservative; progressive).

All coefficients are significant at the 5 per cent level. The table shows that if the distribution of initial capital allocations is uniform (the variable "uniformsize" is 1) the

\footnotetext{
${ }^{4}$ We gratefully acknowledge the support of Michel Schilperoord in running and analysing the simulations.
} 
innovative performance and the size of the sector is less than if the initial capital varies between firms ("uniformsize" is 0). Thus, a heterogeneous capital distribution has a positive influence on both dependent variables, supporting the claims of the structure-oriented scenario. Both the conservative or progressive partner choice mechanisms likewise have a positive influence on the dependent variables, as compared with no collaboration, with the conservative having more effect than the progressive.

The results of the simulation experiments show that neither the agency-oriented scenario nor the structure-oriented scenario can claim primacy. On the one hand, the partner choice decisions of actors for strategic collaboration are significant for the innovative success and the size of the sector; on the other hand the capital distribution, i.e. the structure of the field, is also significant for both dependent variables. In the world of the SKIN model, the two patterns both have an influence.

These overall results can be examined in more detail by considering the mean levels of innovations and firms for specific settings of the independent variables.

The box plots shows the results for simulation experiments for the three partnership strategies: no partners (experiment no. 1-5), conservative (6-10) and progressive (1115). Within each block, the number of big firms is increased from 0 to 300 in steps of 75.

\section{Box plots}



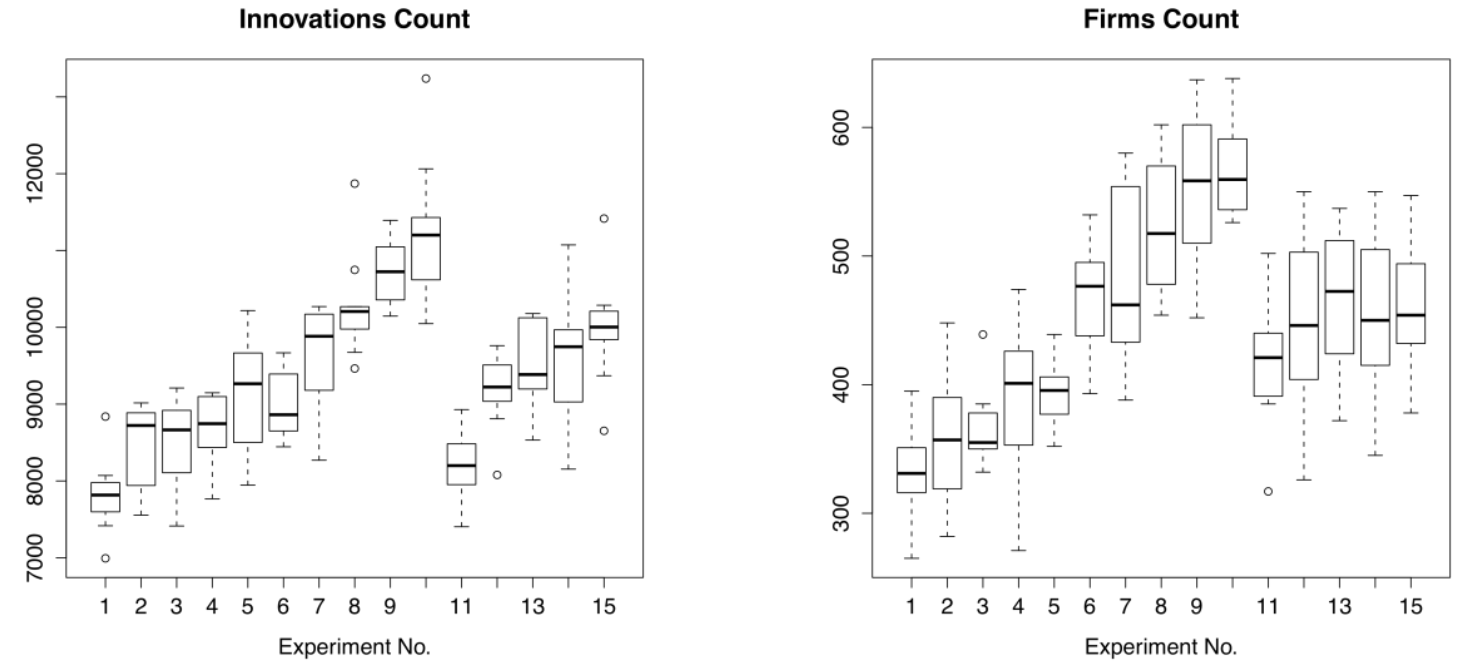

Table 2: Box plots showing the number of innovations and firms for various settings.

Each experiment consisted of 10 runs, with the number of innovations and firms measured at the end of 200 timesteps.

Key:

\begin{tabular}{|l|l|l|l|l|l|l|l|l|l|l|l|l|l|l|l|}
\hline Experiment & 1 & 2 & 3 & 4 & 5 & 6 & 7 & 8 & 9 & 10 & 11 & 12 & 13 & 14 & 15 \\
\hline $\begin{array}{l}\text { No. of big } \\
\text { firms }\end{array}$ & 0 & 75 & 150 & 225 & 300 & 0 & 75 & 150 & 225 & 300 & 0 & 75 & 150 & 225 & 300 \\
\hline $\begin{array}{l}\text { Partner } \\
\text { selection } \\
\text { strategy }\end{array}$ & \multicolumn{10}{|l|}{ No partners } & \multicolumn{10}{|c|}{ Conservative } \\
\hline
\end{tabular}

The results of the box plots show that scenarios with large firms always perform better than scenarios without large firms. Cooperation scenarios always (at least with respect to the mean) perform better than non-cooperative ones and progressive strategies perform less well than conservative strategies. 


\section{Conclusions - Impacts of modelling knowledge-intensive industries for European policy making}

Our result is reflected in efforts to overcome the agency-structure dichotomy. While focussing on partner choice mechanisms as a more agency-oriented pattern, Powell et al. (2005: 58) note that, for the US biotech sector, the "asymmetric distribution of technological, organizational, and financial resources was a key factor in driving early collaborative arrangements in the industry" showing that they do not under-estimate the influence of structural factors such as an unequal capital distribution. Bourdieu, in turn, while focussing on structure-oriented patterns in industry formation, emphasises the importance of agency that is enabled by structural embeddedness, e.g. for price finding strategies in markets: "this vision of action restores a certain free play to agents, without forgetting, however, that decisions are merely choices among possibles, defined, in their limits, by the structure of the field, and that actions owe their orientation and effectiveness to the structure of the objective relations between those engaging in them and those who are the objects of those actions" (Bourdieu 2005: 197).

The mediating position which is supported by the simulation results suggests that actors are able to compensate for structural limitations through strategic collaboration and networking (reference to authors), improving their performance and success. The possibility of handling structural conditions creatively seems to be at the heart of any socio-economic change. And, vice versa, field constraints and structural features enable actors to act strategically within innovation processes. Agency and structure cannot compete on the grounds of primacy but their combinatorial relation is empirically and contextually located between institutional framework conditions, paths 
and structures on the one hand, and creative (re)actions, new governance strategies and network formation of actors on the other hand. Socio-economic theory is required to provide the micro foundation of field structures as well as structure-theoretical embedding of intelligent autonomous actors.

More work is now needed to understand the complex interplay between governance strategies targeting institutional framework conditions (the structure-oriented pattern) and governance strategies supporting collaboration and networking (the agencyoriented pattern). Network policies in public funding schemes for collaborative R\&D, knowledge creation and knowledge diffusion are one of the most important policy instruments used by the European Commission, national, and regional administrations to strengthen the scientific and technological knowledge base in Europe. This is acknowledged in many areas of European economic policy, stemming from the Lisbon agenda ${ }^{5}$.

Strengthening collaboration among innovative actors in Europe is generally agreed to be a key element in improving the competitiveness of European science and industry and in creating the backbone of the European Research Area. To promote the knowledge-based economy in Europe will require the improvement of, on the one hand, the effectiveness and efficiency of network-based policy instruments facing self-organising network formation processes and, on the other, the institutional environment in which they take place, the most important component of which is the political governance regime.

\footnotetext{
5 "The Lisbon agenda is currently the agenda for socio-economic development of the European Union. It was adopted by the European Council of Lisbon in 2000 and it is reshaping many of the Community policies as well as being translated into National Reform programmes in all Member States" (Lisbon agenda group 2007).
} 


\section{References}

Amable, B. (2003), The Diversity of modern Capitalism. Oxford University Press, Oxford. Argyris, C. and D. A. Schoen (1996). Organizational Learning: a theory of action perspective, Addison-Wesley, Reading, MA.

Beije, P. (1998), Technological Change in the Modern Economy: Basic Topics and New Developments. Elgar, Cheltenham.

Bolton, G.E., Katoka, E. and Ockenfels, A. (2005), Cooperation among strangers with limite3d information about reputation, Journal of Public Economics, Vol. 89, 14571468.

Bourdieu, P. (2005), The Social Structures of the Economy. Polity Press, Cambridge. Bourdieu, P. (1992), "The logic of fields," in P. Bourdieu and L. Wacquant (Eds.) An Invitation to Reflexive Sociology, Chicago: University of Chicago Press, 94-114.

Brusoni, S., Prencipe A. and K. Pavitt (2001). Knowledge Specialisation, Organizational Coupling and the Boundaries of the Firm: Why Firms Know More Than They Make? Administrative Science Quarterly, 46: 597-621.

Cantner, U. and Pyka, A. (1998). Absorbing Technological Spillovers. Simulations in an Evolutionary Framework. Industrial and Corporate Change 7(2): 369-397.

Cohen, W.M. and Levinthal, D. (1989). Innovation and learning: the two faces of R\&D. The Economic Journal 99: 569-596.

Casper, S. and H. Kettler (2001), "National institutional frameworks and the hybridization of entrepreneurial business models: the German and UK biotechnology sectors," Industry and Innovation, 8, 5-30.

Casper, S. and F. van Waarden (2006), Innovation and Institutions. A multi-disciplinary Review of the Study of Innovation Systems. Elgar, Cheltenham.

Collins, H. M. (1995), "Science Studies and Machine Intelligence," in S. Jasanoff, G. E. Markle, J. C. Petersen and T. Pinch (Eds.) Handbook of Science and Technology Studies, Thousand Oaks: Sage, 286-301.

Commission of the European Communities (2002), "Benchmarking national R\&D policies: first results," Commission Staff Working Paper, Brussels SEC 129.

Cooke, P. and K. Morgan (1998), The Associational Economy, Firms, Regions and Innovation. Oxford University Press, Oxford. 
D'Aspremont, C. and A. Jacquemin (1988), "Cooperative and non-cooperative R\&D in duopoly with spillovers," American Economic Review, 78, 1133-1137.

De Geus, A. (1997). The Living Company, Brealy, London.

Dewey, J. (1938). Experience and Education, Collier, New York.

Duncan, R.B. (1974). Modifications in decision structure in adapting to the environment: some implications for organizational learning, Decision Sciences 5: 705-725.

Eliasson, G. (1995), "General purpose technologies, industrial competence and economic growth," Working Paper, Royal Institute of Technology, Stockholm.

Feldman, M., J. Francis and J. Bercovitz (2005), "Creating a cluster while building a firm: entrepreneurs and the formation of industry clusters," Regional Sciences, 39, 129142.

Garcia, R., D.T. Dunn and L.A. Smith (forthcoming a). Boundary spanners and social networks surrounding research centers. NSF 04-556 Partners for Innovation Program. Working Paper.

Garcia, R., D.T. Dunn and L.A. Smith (forthcoming b). Performance of knowledge interactions between public research centres and industrial firms: an application for Spanish public research centres based on project-level data. Working Paper.

Granovetter, M. (1985), "Economic action and social structure: the problem of embeddedness," American Journal of Sociology, 91, 481-510.

Hall, P. and D. Soskice (Eds.) (2001), Varieties of Capitalism. Oxford University Press, Oxford.

Hedberg, B. (1981). B. Hedberg, How organizations learn and unlearn, in P. C. Nystrom and W. H. Starbuck, eds., Handbook of Organizational Design, Oxford University Press, Oxford.

Knight, F.H. (1921), Risk, Uncertainty and Profit. Chicago.

Lisbon Agenda Group (2007): http://www.mariajoaorodrigues.eu/lisbon-agenda/group/ Malerba, F., R. Nelson, L. Orsenigo and S. Winter (1999), "History friendly models of industry evolution: the computer industry," Industrial and Corporate Change, 8, 3-40. Malerba, F. (2002), "Sectoral systems of innovation and production," Research Policy, 31, 247-264.

Martin, S. (2003), "The evaluation of strategic research partnerships," Technology Analysis \& Strategic Management, 15, 159-176. 
Michael, D.M. (1973). On learning to plan and planning to learn, Jossey-Bass, Hoboken, NJ.

Michelet, R. (1992), Forming successful strategic marketing alliances in Europe, Journal of European Business, Vol. 4, 11-15.

Nelson, R. (2001), "Evolutionary perspectives on economic growth," in K. Dopfer (Ed.)

Evolutionary Economics, Boston, Dordrecht, London: Kluwer Academic Publishers.

Pavitt, K. (1987), 'The objectives of technology policy,' Science and Public Policy, 14, 182 188. Reprinted in Pavitt (1999).

Petit, P. and B. Amable (2001), "The Diversity of Social Systems of Innovation and Production during the 1990s," Working Paper CEPREMAP \# 2001 - 15.

Powell, W. W. (1990), "Neither market nor hierarchy. network forms of organization," Research in Organizational Behavior, 12, 295-336.

Powell, W. W., D. R. White, K. W. Koput and J. Owen-Smith (2005), "Network dynamics and field evolution: the growth of inter-organizational collaboration in the life sciences," American Journal of Sociology, 110, 1132-1205.

Pyka, A. and G. Kueppers, G. (2003) (eds.), Innovation Networks - Theory and Practice, Edward Elgar, Cheltenham.

Pyka, A. and P.P. Saviotti (2003). Innovation Networks in the Biotechnology-based Industries, in: A. Pyka and G. Kueppers (eds.), Innovation Networks - Theory and Practice, Edward Elgar, Cheltenham: 75-107.

Pyka, A. and P.P. Saviotti (2005). The Evolution of R\&D Networking in the Biotech Industries. International Journal of Entrepreneurship and Innovation Management 5(1/2): 49-68.

Weber, M. (2003). Innovation networks and the transformation of large socio-technical systems: the case of combined heat and power technology. In: A. Pyka and G. Kueppers (eds.), Innovation Networks - Theory and Practice, Edward Elgar, Cheltenham: 133-165.

Windrum, P. (2003). The role of knowledge-intensive business services (KIBS) in ecommerce. In: A. Pyka and G. Kueppers (eds.), Innovation Networks - Theory and Practice, Edward Elgar, Cheltenham: 108-132.

Winter, S.G. (1984). Schumpeterian Competition in alternative Technological Regimes, Journal of Economic Behaviour and Organization 5: 237-261. 
Petra Ahrweiler is Professor of Innovation and Technology Management at UCD, Director of UCD's newly established Innovation Research Unit IRU, and a permanent Research Affiliate of the Engineering Systems Division at MIT, USA. She has a background in science and technology studies, sociology of innovation, and policy research. Her main research interests are innovation networks, Science, Technology and Innovation Policy, and modelling the emergence of knowledge-intensive industries such as ICTs and biotech.

Nigel Gilbert is Professor of Sociology and Director of the Centre for Research in Social Simulation at the University of Surrey, Guildford, United Kingdom. His research interests include innovation, agent-based models and research methods. He is the author of Simulation for the Social Scientist (with Klaus G. Troitzsch), (2005) Open University Press and Agent Based Models (2007) Sage Publications Inc.

Andreas Pyka's research topics are Neo-Schumpeterian economics and innovation research with a particular focus on collective innovation processes and the industrial organisation of innovation. Methodologically, he is engaged in the field of agent-based computational approaches as well as in approaches coming from complexity theory. He is a Professor of innovation economics at the University of Stuttgart-Hohenheim. 